\title{
Experimental bed active-layer survey with active RFID scour chains: Example of two braided rivers (the Drac and the Vénéon) in the French Alps
}

\author{
Guillaume Brousse ${ }^{1, *}$, Frédéric Liébault ${ }^{2}$, Gilles Arnaud-Fassetta ${ }^{1}$, Daniel Vazquez-Tarrio ${ }^{3}$ \\ ${ }^{1}$ PRODIG, Place Paul Ricoeur, 75013 Paris, France \\ ${ }^{2}$ Université Grenoble Alpes, IRSTEA, 2 rue de la Papeterie, 38402 Saint-Martin-d'Hères, France \\ ${ }^{3}$ INDUROT, University of Oviedo, 33600 Mieres, Spain
}

\begin{abstract}
An innovative scour chains device composed of active UHF RFID tags is proposed to survey the bed active layer. This device is tested on three cross-sections deployed along two large Alpine braided rivers: the Drac and the Vénéon. A specific field deployment procedure is developed, using a technique of drilling with a tube and a jack-hammer. After each flood, the device allows recording presence/absence of active tags inside a scour chain column. This provides the maximum scouring depth of the bed at the position of the column, and the topographic resurvey of the channel provides the net fill depth. Results show that bed active layer can reach up to $1.43 \mathrm{~m}$ during high flow conditions and remains $<0.1 \mathrm{~m}$ during low and moderate flows. The main advantage of this technology against traditional scour chains is the rapidity and easiness with which the scouring depth is obtained after a flow event, notably under conditions of massive net deposition after the flow. This technology is therefore particularly suitable for large braided rivers, where traditional scour chains necessitate too much field efforts for their relocation, and can be rapidly lost under deep active layers.
\end{abstract}

\section{Introduction}

Traditional scour chains proposed by Leopold et al. [1] are commonly used in river channels to constrain post-flood scour and fill depths [2-3]. This is an efficient device for measuring the bed active layer ( $d_{b}$; vertical magnitude of the active channel; [4]) because scour chains are very cheap and they do not require the presence of an operator for measurement during flow events. For these reasons, scour chains have been largely used in many case studies with geomorphological or ecological aims $[5,6,7,8,9,10,11,12,13,14]$.

However, if scour chains lifetime could be very long, laborious field efforts are required for the recovery and relocation of scour chains, especially in mountain streams characterized by coarse grain-size distributions and by substantial vertical mixing of the bed during flow

* Corresponding author: guillaume.brousse@univ-paris-diderot.fr 
events. This explains why scour chains have not been used so much in such harsh environmental conditions.

Recently, several innovations permit some improvements of the "conventional" scour chain method. Gendaszek et al. [15] have proposed to use a chain composed by two " Accelerometers Scour Monitors" (ASMs). This device permits to record the scour and fill cycle along a complete hydrological season using a data logger, but it does not avoid laborious field works for the recovery of chains - even if pit tags could be inserted on the data logger [16] - and remains uncertain for bed active layer surveying. Papanicolaou et al. [17-18] have

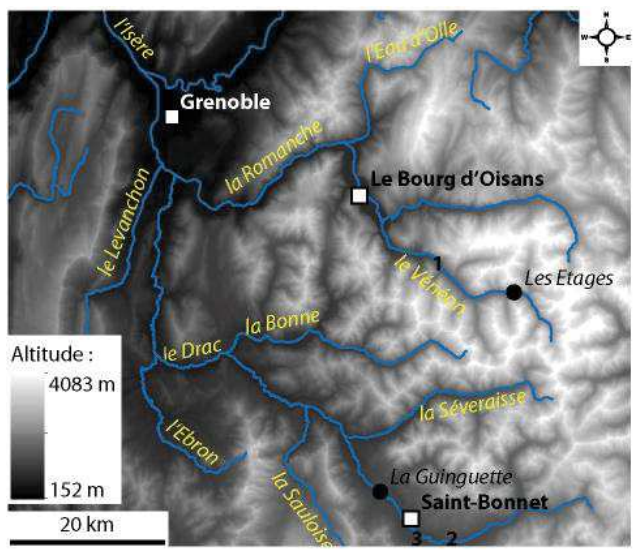

Fig. 1. Localisation of study sites. 1: PL site; 2: CHAB site; 3: ZR site. adapted « conventional chains » with passive RFID tags $(133.4 \mathrm{kHz})$, but this device needs a fixed antenna with continuous power, which limits its use for active layer survey in a natural environment. It is a similarly problem with the resistance chain [19], which necessitates a complete station with a GSM modem powered by a solar panel. Recent innovations with active RFID tags used for sediment tracking [20-21] offer new opportunities to improve scour chains. In fact, this technology allows us to detect PIT tags in surface (range of $80 \mathrm{~m}$ according to ELA Innovation(C), in subsurface, and under water [21] positions. Active tags have smaller lifetime than passive ones but there is no signal collision and each tag could be individualized when they are very close to each other [20].

This paper aims to describe and test a new experimental device for monitoring the bed active layer of mountain streams based on the use of a new generation of scour chains called "RFID scour chains". Methodological objective is to test the use of RFID scour chains under critical conditions of active layer dynamics, for which traditional scour chains are not really adapted (i.e., too much field efforts for low recovery rates).

This new device was implemented along two braided mountain streams (Fig. 1; Tab. 1). In May 2016, two RFID scour chains were deployed in the Vénéon River, immediately upstream from the Plan-du-Lac power plant (PL site). This $2.5-\mathrm{km}$ long braided reach is characterized by a $1.6 \%$ slope and a high sediment supply (presence of moraine and scree directly connected to the channel), which explains intense bedload transport conditions.

Table 1. Hydromorphological study site context.

\begin{tabular}{|c|c|c|c|}
\hline River & Vénéon & \multicolumn{2}{|c|}{ Drac } \\
\hline Site & PL [22] & CHAB [23] & ZR [23] \\
\hline Drainage area (in $\mathbf{~ k m}^{\mathbf{}}$ ) & 235 & 308 & 336 \\
\hline Channel slope (in \%) & 1.60 & 0.97 & 0.81 \\
\hline $\boldsymbol{D}_{\mathbf{5 0} \text { (in } \mathbf{~ m m ) ~}}$ & 38.2 & 65.0 & 60.5 \\
\hline $\boldsymbol{D}_{\mathbf{8 4}}$ (in mm) & 69.2 & 99.0 & 97.2 \\
\hline Width (in m) & 141.5 & 109.4 & 81.4 \\
\hline $\boldsymbol{\tau}_{\mathbf{c 8 4}}$ * & 0.0300 & 0.0264 & 0.0255 \\
\hline Number of RFID scour chains & 2 & 5 & 3 \\
\hline
\end{tabular}

$\tau_{\mathrm{c} 84} *$ (critical adimensional shear stress for the $D_{84}$ of the bed=0.56 $S+0.021$, with $S=$ channel slope in $\mathrm{m} / \mathrm{m}[24]$. 
In January 2017, eight RFID scour chains were deployed at two sites, along the Upper Drac River upstream from Saint-Bonnet-en-Champsaur, which differ mostly by active channel width (Tab. 1). This river is characterized by a mean slope of around $1 \%$ and an important bedload transport. The study reach is divided in three different morphological units. The first one is the downstream ending of a natural braided reach, which correspond to the principal sediment source of the area (CHAB site). The second one is a wandering 3-km long section making a transition with the altered 3.6-km long reach of Saint-Bonnet-en-Champsaur, which was restored in 2014 (ZR site).

\section{Materials and methods}

The general principle of RFID scour chain is to replace traditional metallic chains with a column of RFID tags. This new scour chain is deployed in three main steps: (i) equipment preparation (tag programming and design of the drilling system); (ii) onsite deployment (drilling with a jack-hammer, tags insertion and topographic survey; Fig. 2); (iii) RFID scour chain survey (tag detection and topographic survey).

\subsection{Drilling technique for RFID scour chains deployment}

Used tags are COIN ID active UHF RFID tags (433.92 MHz) from ELA Innovation (C) distributed by CIPAM (C). Tracer dimensions are $36 \mathrm{~mm}$ in diameter, and $10 \mathrm{~mm}$ in thickness; they weigh $11 \mathrm{~g}$ and can be submerged in water (IP68 standard). The emission periodicity has been set at $4.3 \mathrm{~s}$ to maximize tags lifetime ( $>5$ years).

A thermic jack-hammer was used to drive a 5-cm diameter metallic tube into the alluvial bed, using a percussion drilling technique (Fig. 2). Percussion accessories include a chisel, a striking ring, a lost spike and a steel tube (with a diameter of $5 \mathrm{~cm}$ and a length adapted to the chosen burial depth). Once RFID tags have been inserted into the column, the steel tube is removed from the bed using an extraction device. Unlike conventional chains, RFID scour chains do not have any anchor or any link between tags. Small pieces of wood are used to create a column of tags positioned at regular intervals into the bed.

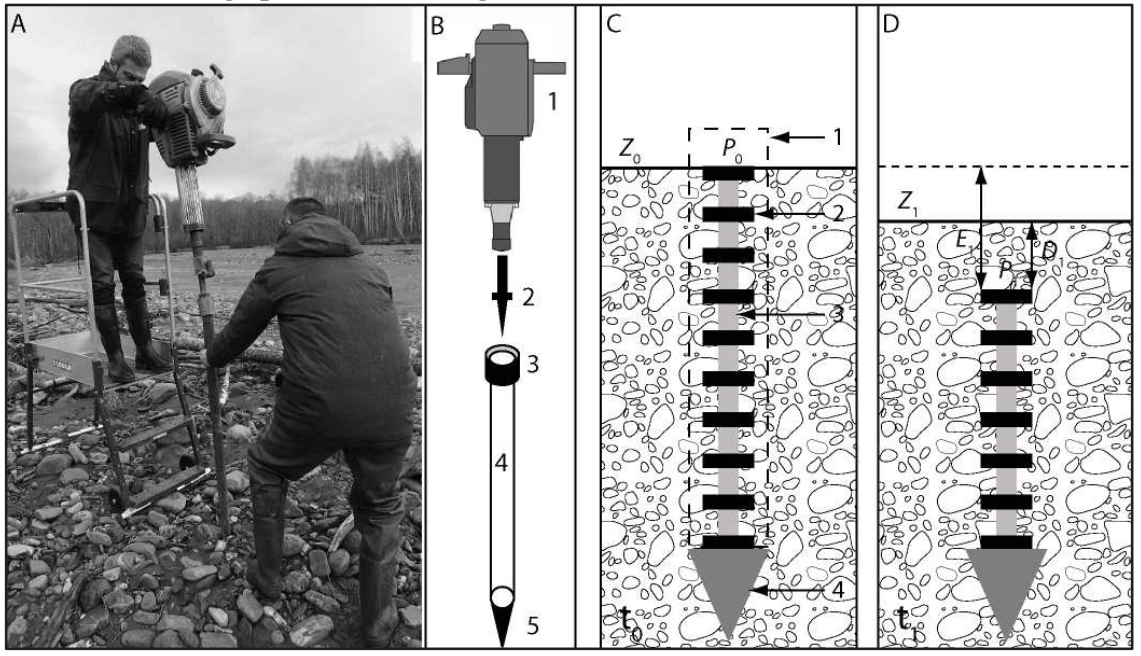

Fig. 2. RFID scour chain deployment and survey. A: Percussion drilling. B: Drilling device details. 1: jack-hammer; 2: modified chisel; 3: striking ring; 4: steel tube; 5: lost spike. C: Initial RFID scour chain. 1: buried steel tube; 2: UHF RFID tag; 3: pieces of wood; 4: lost spike. D: First survey. $Z=$ active channel altitude; $E=$ maximum scour depth; $P=$ depth of the shallowest tag; $D=$ =maximum fill depth. 
It generally takes less than 20 min to deploy a 1-m depth RFID column into the alluvial bed. The lost spike can break cobbles-pebbles but it mostly allows facilitating a way between the coarsest grains. Tube extraction is carried out thanks to a manual puller positioned in line with a tripod and a gentle extraction allows sediment to progressively cover tags without disturbing the bed structure. In the Vénéon River, 25 tracers were divided into two RFID scour chains with a depth of $1.1 \mathrm{~m}$ (CV1, 13 tags) and $1 \mathrm{~m}$ (CV2, 12 tags). The average spacing of tags is $8.3 \mathrm{~cm}$. On the Drac River, 61 tags were inserted in 8 chains. Those of the "CHAB" site were systematically buried at $1 \mathrm{~m}$ and less of $0.5 \mathrm{~m}$ for the "ZR" site because of presence of bedrock in subsurface. Spacing tags respect a systematic interval of $10 \mathrm{~cm}$.

\subsection{RFID scour chain survey}

Field equipment is composed of a reader (SCIEL READER R) connected to a detection antenna (SLENDER III). These two elements are connected to a workstation equipped with the ELOG.exe software, which makes it possible to visualize and record detection of tags. The device is completed by a RTK-GPS, which allows locating the chain and measuring the cross-section profile for each survey. Tags detection does not exceed 5 min per column and topographic survey does not exceed $20 \mathrm{~min}$ for a braided cross section $(<110 \mathrm{~m})$.

After each flood, it is possible to know which tags are still in place and which ones have disappeared. This information makes it possible to constrain the maximum depth of scour at the position of the chain $(E)$ according to $E=|P|$ with $P=$ depth of the shallowest recovered PIT tag (in m). Topographic survey gives the fill depth $(D)$ according to $D=E-\left(Z_{0}-Z_{1}\right)$ with $Z_{0}=$ initial altitude (in $\mathrm{m}$ a.s.l.) and $Z_{1}=$ new altitude (in $\mathrm{m}$ a.s.l.). Finally, vertical evolution $\left(\Delta_{\mathrm{H}}\right.$ in $\mathrm{m}$ ) is given by $\Delta_{\mathrm{H}}=-E+D$ and bed active layer $\left(\mathrm{d}_{\mathrm{b}}\right.$ in $\mathrm{m}$ ) is given by $\mathrm{d}_{\mathrm{b}}=E+D$.

\section{Results}

\subsection{Hydromorphological monitoring conditions}

Results are based on several surveys after RFID scour chain deployment (Fig. 3). The Vénéon River has benefited from three surveys (on 28/07/2016, "V1"; on 22/09/2016, "V2", and on 20/09/2017, "V3") since the deployment whereas only one survey (on 13/08/2017, "D1") was done on the Drac River.

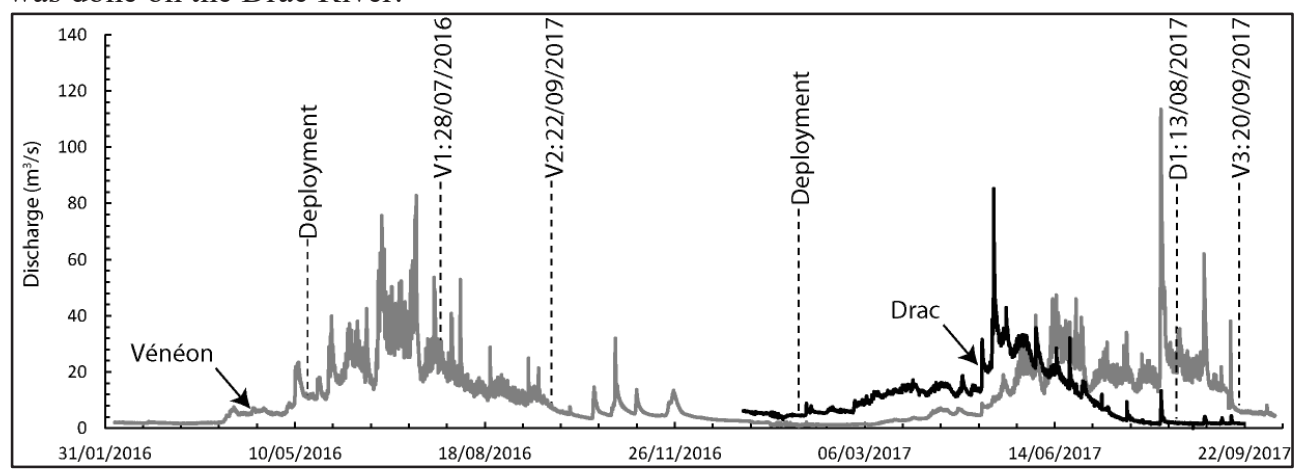

Fig. 3. Hydrological conditions of RFID scour chains surveys. Discharge (in $\mathrm{m}^{3} / \mathrm{s}$ ) of the Vénéon River is obtained from the Étages gauging station $\left(103 \mathrm{~km}^{2}\right.$, EDF; Fig. 1) with a linear relation: $Q_{\mathrm{PL}}=2.3 Q_{\mathrm{E}}$ (with $Q_{\mathrm{PL}}=$ discharge $\left(\right.$ in $\mathrm{m}^{3} / \mathrm{s}$ ) at the « $\mathrm{PL}$ » site, and $Q_{\mathrm{E}}=$ discharge $\left(\right.$ in $\mathrm{m}^{3} / \mathrm{s}$ ) at the Étages gauging station; [22]). Discharge (in $\mathrm{m}^{3} / \mathrm{s}$ ) of the Drac River is provided by the Guinguette gauging station (510 $\mathrm{km}^{2}$, EDF; Fig. 1). We considered that the hydrology of the study site is similar to that of the Guinguette 
gauging station, even considering that the Séveraissette River may contribute increasing discharge (empirical relation is not available).

The critical adimensional shear stress $\left(\tau_{\mathrm{c}}{ }^{*}\right)$ have been exceeded very frequently on the Vénéon River, and a quasi-continuous bedload transport is inferred from hydraulic computations during the snowmelt flows (Tab. 2). This is not the case for the Drac River, where bedload transport was active during a much lower time period (Tab. 2). A higher peakflow discharge was observed for the Vénéon River, as well as higher $\tau^{*} / \tau_{\mathrm{c}} *$ ratios (Tab. 2 ). This suggests bedload transport close to full mobility conditions in the Vénéon River but not in the Drac River [24].

Table 2. Hydrodynamic conditions during the investigated period.

\begin{tabular}{|c|c|c|c|c|c|}
\hline River & \multicolumn{3}{|c|}{ Vénéon } & \multicolumn{3}{c|}{ Drac } \\
\hline Site & \multicolumn{3}{|c|}{ PL } & CHAB & ZR \\
\hline Survey period & V1 & V2 & V3 & D1 & D1 \\
\hline Maximum peak flow $\left(\right.$ in $\left.\mathbf{~ m}^{\mathbf{3}} / \mathbf{s}\right)$ & 82.8 & 53.0 & 113.5 & 85.1 & 85.1 \\
\hline Maximum $\boldsymbol{\tau}_{\mathbf{8 4}} *$ & 0.055 & 0.053 & 0.058 & 0.030 & 0.031 \\
\hline Maximum $\boldsymbol{\tau}_{\mathbf{8 4}} * \boldsymbol{\tau}_{\boldsymbol{c} 84} *$ & 1.83 & 1.76 & 1.93 & 1.14 & 1.18 \\
\hline $\begin{array}{c}\text { \% of time with active bedload } \\
\text { transport }\left(\boldsymbol{\tau}_{\mathbf{8 4}} * \boldsymbol{\tau}_{\boldsymbol{c} 8} * \boldsymbol{*}\right)\end{array}$ & 100 & 96 & 39 & 3 & 17 \\
\hline
\end{tabular}

Hydraulic data have been computed according to GTM model [24-25] and are based on field data (Tab. 1, [22-23]). $\tau_{84} *=R S /\left(1.65 D_{84}\right)$, with $R=$ hydraulic radius in $\mathrm{m}$ [24].

\subsection{Spatio-temporal variability of the bed active layer}

Results of the active layer surveys for the two sites are presented in Fig. 4 and Tab. 3. The first two surveys of the Vénéon River (V1 and V2) show that RFID scour chains remained intact, resulting in null erosion or less than $0.10 \mathrm{~m}$. Topographic monitoring shows a fill of less than $0.10 \mathrm{~m}$ at the chain positions and morphological changes concentrated in secondary channels with a small deposit $\left(+1.15 \mathrm{~m}^{2}\right)$ for $\mathrm{V} 1$ and then a small erosion $\left(-3.4 \mathrm{~m}^{2}\right)$ for $\mathrm{V} 2$. During the last survey (V3), morphological changes were much more important. The first chain (CV1) shows strong scour $(E=0.53 \mathrm{~m})$ and a large fill $(D=0.90 \mathrm{~m})$ while the second (CV2) shows smaller variations $(E=0.32 \mathrm{~m}$ and $D=0.69)$. For each chain, budget is positive $(0.37 \mathrm{~m}$ in CV1 and $0.38 \mathrm{~m}$ in CV2) and the mean active layer extends over $1.20 \mathrm{~m}$. At the cross section scale, budget is largely positive $\left(+11 \mathrm{~m}^{2}\right)$. The avulsion of the main channel from the left to the right bank during the flood explains the magnitude of the active layer.

At the "CHAB" site, the survey (D1) shows heterogeneous scour and fill processes. Only the closest chain to the main channel records scour $(\mathrm{CD} 1 ; E=0.70 \mathrm{~m})$ and the four others $(\mathrm{CD} 2$, $\mathrm{CD} 3, \mathrm{CD} 4$, and $\mathrm{CD} 5)$ remained intact resulting in null erosion or less than $0.10 \mathrm{~m}$. Topographic survey shows a $0.21 \mathrm{~m}$ fill in CD1, an insignificant deposit in CD2 and CD3 due to the RTK-GPS precision $( \pm 0.05 \mathrm{~m})$, and a low deposit in CD4 and CD5 $(0.10<D<0.20$ $\mathrm{m})$. The cross-section budget is almost stable $\left(-0.24 \mathrm{~m}^{2}\right)$. Most of the morphological adjustments are confined to the right bank because the main channel has migrated $10 \mathrm{~m}$ to the left, leaving in place an alluvial bar. This migration explains scour observation in CD1 and the active layer magnitude $(0.91 \mathrm{~m})$.

At the ZR site, the D1 survey shows that chain located in the left bank (CD7) records a total erosion ( $100 \%$ of mobile tags; $E \geq 0.30 \mathrm{~m}$ ) and the chain located in the right bank (CD6) shows no mobile tag $(E \leq 0.10 \mathrm{~m})$. Topographic survey shows a minimum fill of $0.14 \mathrm{~m}$ in CD7 ( $D_{\max }$ is unknown because the uncertainty of $\left.E_{\max }\right)$, and a thin fill in CD6 $(D=0.06 \mathrm{~m})$. In the cross section, surface budget is positive $\left(+3.3 \mathrm{~m}^{2}\right)$. Most of the morphological adjustments concern 
the left bank where a new channel has formed between the main channel and the secondary channel. This connection explains erosion observed in CD7. The CD8 chain is located $57 \mathrm{~m}$ downstream from the transect and forms the tip of a triangle with CD6 and CD7. It is characterized by total erosion ( $100 \%$ of mobile tags; $E \geq 0.30 \mathrm{~m}$ ) and a minimum fill of 0.11 $\mathrm{m}\left(D_{\max }\right.$ is unknown because the uncertainty of $\left.E_{\max }\right)$.

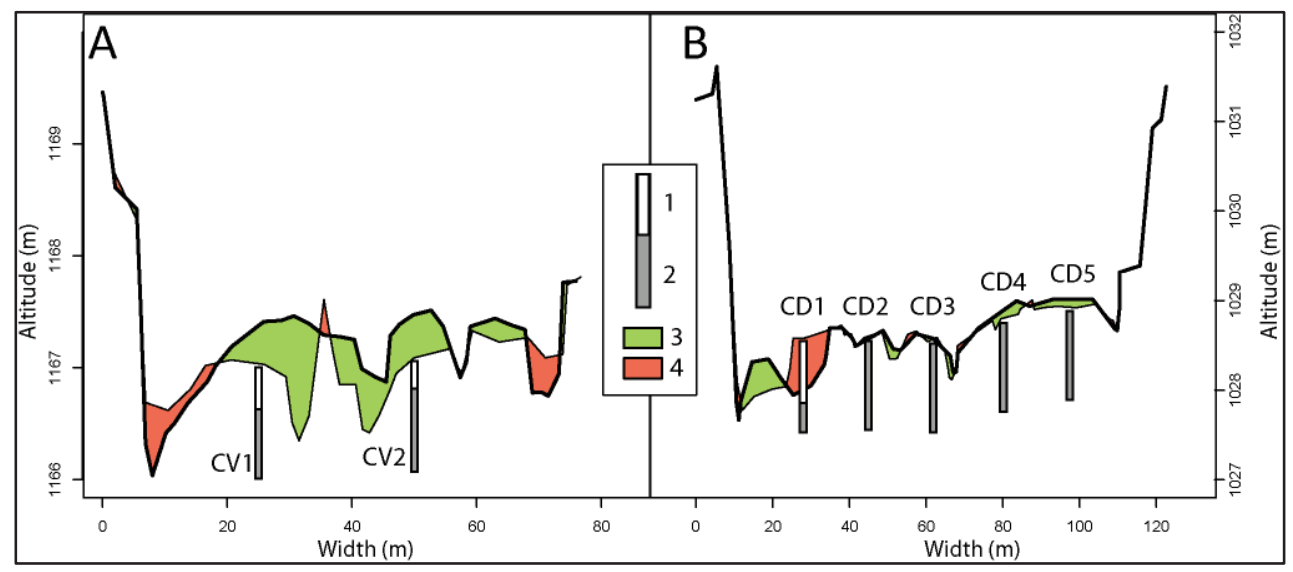

Fig. 4. Most significant examples of spatio-temporal variability of the bed active layer. A: Vénéon River (PL) in V3 survey; B: Drac River (CHAB) in D1 survey. 1: mobile tags; 2: immobile tags; 3: fill surface between two surveys; 3 : scour surface between two surveys. This 1-D cross-section comparison is produced under "R" software thanks to the code proposed by Lise Vaudor (ENS Lyon, UMR 5600 EVS).

Table 3. Scour and fill results.

\begin{tabular}{|c|c|c|c|c|c|c|c|c|c|c|c|c|c|c|}
\hline Site & \multicolumn{6}{|c|}{ Vénéon (PL) } & \multicolumn{5}{|c|}{ Drac (CHAB) } & \multicolumn{3}{|c|}{ Drac (ZR) } \\
\hline Survey & \multicolumn{2}{|c|}{ V1 } & \multicolumn{2}{|c|}{$\mathrm{V} 2$} & \multicolumn{2}{|c|}{ V3 } & \multicolumn{8}{|c|}{ D1 } \\
\hline Column & CV1 & $\mathrm{CV} 2$ & CV1 & CV2 & CV1 & CV2 & $\mathrm{CD} 1$ & CD2 & CD3 & CD4 & CD5 & CD6 & CD7 & CD8 \\
\hline Scour (in m) & 0 & 0 & 0 & 0 & 0.53 & 0.32 & 0.70 & 0 & 0 & 0 & 0 & 0 & $>0.30$ & $>0.30$ \\
\hline Fill (in m) & 0.06 & 0.08 & 0.08 & 0.03 & 0.90 & 0.69 & 0.21 & 0.02 & 0.01 & 0.10 & 0.10 & 0.06 & 0.14 & 0.11 \\
\hline $\mathbf{d}_{\mathrm{b}}($ in $\mathbf{m})$ & 0.06 & 0.08 & 0.08 & 0.03 & 1.43 & 1.01 & 0.91 & 0.02 & 0.01 & 0.10 & 0.10 & 0.06 & 0.44 & 0.41 \\
\hline$S_{\mathrm{e}}($ in $\mathrm{m})$ & \multicolumn{6}{|c|}{0.08} & \multicolumn{6}{|c|}{0.10} & \multicolumn{2}{|c|}{$>0.10$} \\
\hline$F_{\mathrm{e}}($ in $\mathrm{m})$ & \multicolumn{6}{|c|}{0.05} & \multicolumn{6}{|c|}{0.05} & \multicolumn{2}{|c|}{0.05} \\
\hline RMSE (in m) & \multicolumn{6}{|c|}{0.09} & \multicolumn{6}{|c|}{0.11} & \multicolumn{2}{|c|}{$>0.11$} \\
\hline
\end{tabular}

RMSE $=\left(S_{\mathrm{e}}{ }^{2}+F_{\mathrm{e}}{ }^{2}\right)^{0.5}$ with $S_{\mathrm{e}}=$ Scour error $(0.08 \mathrm{~m}$ for the Vénéon River and $0.10 \mathrm{~m}$ for the Drac River $)$ and $F_{\mathrm{e}}=$ Fill error (RTK-GPS precision $=0.05 \mathrm{~m}$ ). CD7 and CD8 RMSE are $>0.11 \mathrm{~m}$ because of the uncertainty of $E_{\max }$.

\section{Discussion}

\subsection{Feedback from the field experiment}

RFID scour chains and its specific drilling device offer considerable time saving for deployment (use of a jack-hammer) and for monitoring (use of the RFID technology) in comparison to traditional scour chains $[1,2,3,4]$. This device proved to be successful for the measurement of the active-layer thickness under conditions of strong channel deformation in 
active, braided rivers. It is a real advantage in comparison with metallic scour chains, which are frequently lost and very difficult to relocate when deeply buried.

The spacing of PIT tags within the RFID column has a direct effect on the cost of the column (around $38 € /$ tag) and on the resolution with which the scour depth can be obtained. In our case, the average tag spacing corresponds to the $D_{90}$ on the Vénéon River and to $0.9 D_{90}$ on the Drac River. The resolution is lower than the one from traditional scour chains [14] but we conserve standards indication from Laronne et al. [2]. This spacing link seems to be consistent for coarse-grained channels, but not necessary for sandy channels. However, it is theoretically possible to increase the number of tags inside the column to increase the resolution of the scour monitoring, up to a maximum resolution of $10 \mathrm{~mm}$, corresponding to the thickness of the tag (analog to the link length of metallic chains).

Drilling of the bed to insert the tube is not a problem if the bed layer is sufficiently thick and/or there is no bedrock in the subsurface. In this condition, whatever the nature (schist, granite or limestone) or the texture (presence or absence of armor, presence or absence of sandy-silty matrix), tube has buried over more than one meter in few minutes. However, in case of coarse grain size, the lost spike is indispensable for drilling.

In case of morphogeneous event, we observe that the greatest $d_{b}$ value correspond to a high $\tau^{*} / \tau_{\mathrm{c}} *$ ratio $(\mathrm{V} 3)$ whereas a poor $\mathrm{d}_{\mathrm{b}}$ value correspond to a low $\tau^{*} / \tau_{\mathrm{c}} *$ ratio (D1; Tab. 2 and 3 ). This positive correlation between $\mathrm{d}_{\mathrm{b}}$ and $\tau^{*} / \tau_{\mathrm{c}}{ }^{*}$ seems to confirm the hypothesis that the active layer can be modeled from the adimensional shear stress [13].

\subsection{Device prospects}

During survey "D1", some mobile PIT tags were detected more than $1 \mathrm{~km}$ from the CD1 chain. It is therefore possible to obtain data on distance of transport of the bedload from tags used for RFID scour chain. For this, it is necessary to change the density of the PIT tag because is too low $\left(1.74 \mathrm{~g} / \mathrm{cm}^{3}\right)$ and to maintain a size/weight ratio to interpret mobility. According to Cassel et al. [26] it is conceivable to replace our tags by artificial pebbles equipped with active PIT tags. This makes it possible to constrain both the spatio-temporal variability of the bed active layer and the mobility of subsurface coarse sediment. The diameter of the tube is limiting for tracker size and we cannot reproduce surface grain size. But this problem is bypassed in armored context because of sediment surface being largely coarser than subsurface sediment [27]. For the moment, active RFID signal ("RSSI"; [21]) give a mean 3-D spatial resolution and we cannot make a clear difference between horizontal and vertical accuracy. In these conditions, use of artificial pebbles could induce difficulties for RFID scour chain interpretation. In case of low mobility, artificial pebbles could stay close to the column and mask scour information whereas a simple tag is directly transported downstream because of lower density.

\section{Conclusions}

All RFID scour chains deployed in the Vénéon River and the Drac River proved to be efficient for the reconstruction of the active layer geometry, even during flow events that generate a strong vertical mobility of river channels (above 1-m deep). Our specific drilling and detection equipment allow technical optimization of traditional scour chains employment. Thus, bed active layer survey of large braided rivers becomes less laborious. Active RFID technology makes it possible to bypass excavation step (even if excavation is indispensable for column resetting) and tag lifetime maximize survey potential.

Our field data show the interest of this new device for monitoring braided river responses to flow events and for the understanding of the link between active-layer thickness and hydraulic forces. These technical optimizations have to be relativized in regard to the extra 
cost generated by the RFID scour chain, which is significantly more expensive than metallic scour chains. But this extra cost could be compensated by coupling scour and fill monitoring and sediment tracking with active RFID device, and by saving time during post-flow field works.

\section{Acknowledgements}

We thank IRSTEA for the design of drilling device and the RTK-GPS loan. This work benefited from the financial support of the Interreg Alpine Space Hymocares project, EDF and AFB.

\section{References}

1. L.B. Leopold, W.W. Emmet, R.M. Myrick. US Geol. Sur. Prof. Paper, 352, 60 (1966).

2. J.B. Laronne, D.N. Outhet, P.A. Carling, T.J. Mc Cabe. Catena, 22, 7 (1994).

3. P.A. Carling. River Channel, Environment and Process (Blackwell, Oxford 1984).

4. F. Liébault, J.B. Laronne. Geodinamica Acta, 21, 11 (2008).

5. M.A. Hassan. ESPL, 15, 15 (1990).

6. T.E Lisle, R.E. Eads. USDA For. Ser. Res, note PSW, 411 (1991).

7. R.K. Nawa, C.A. Frissell. North Amer. Jour. of Fish. Manag, 13, 5 (1993).

8. D.M. Powell, R. Brazier, J. Wainwright, A. Parsons, J. Kaduk. Water Resour. Res., 41, W05019 (2005).

9. S. Rodrigues, J.G. Bréhéret, F. Moatar, J.J. Macaire. C. R. Geoscience, 337, 8 (2005).

10. A.J. Rollet. Etude et gestion de la dynamique sédimentaire d'un tronçon fluvial à l'aval d'un barrage: le cas de la basse vallée de l'Ain (Lyon 3, 305, 2007).

11. M. Chapuis, S. Dufour, M. Provansal, B. Couvert, M. De Linares. Geomorphology, 231, $11(2015)$.

12. J.M. Turowski, K.L. Cook. ESPL, 42, 18 (2017).

13. J.K. Haschenburger. Water Resour. Res., 35, 30 (1999).

14. F. Liébault, P. Clément. Géo. Phys. et Quat., 611, 13 (2007).

15. A.S. Gendaszek, C.S. Magirl, C.P. Konrad, C.R. Czuba, M.D. Marineau. Proceedings of the Hydraulic Measurements and Experimental Methods Conference (Snowbird, Utah, 6, 2012).

16. L. Olinde, J.P.L. Johnson. Water Resour. Res., 51, 18 (2015).

17. A.N. Papanicolaou, M. Elhakeem, A. Tsakiris. Iowa Highway Research Board Final Report, Project TR-595 (2010).

18. A.N. Papanicolaou, I.V. Moustakidis, A.G. Tsakiris, C.G. Wilson, B. Abban. Iowa Highway Research Board Final Report, Project TR-617 (2014).

19. C. Berger, B.W. McArdell, B. Fritschi, F. Schlunegger. Water Resour. Res., 46 (2010).

20. H. Piégay, F. Arnaud, M. Cassel, T. Dépret, A. Alber, K. Michel, A.J. Rollet. Bul. de la Soc. Géo. de Liège, 67, 14 (2016).

21. M. Cassel, T. Dépret, H. Piégay. ESPL, 42, 14 (2017).

22. IRSTEA. Rapport technique pour le compte d'EDF-CIH, 75 (2016).

23. G. Brousse, F. Liébault, G. Arnaud-Fassetta. IAG 2017 (New Delhi, Inde, 2017).

24. A. Recking, Water Resour. Res., 52, 15 (2016).

25. A. Recking, F. Liébault, C. Peteuil, T. Jolimet. Evaluation des formules de transport solide en rivière avec prise en compte de l'échelle temporelle (IRSTEA, 2008).

26. M. Cassel, H. Piégay, J. Lavé. ESPL, 42, 15 (2016)

27. D.I., Bray, M. Church. Jour. of the Hyd. Div., Amer. Soc. of Civ. Eng., 106, 3 (1980). 